\title{
To Learn from the Australian Course Management Mode and to Construct a Course Management System that Adapts to China's Higher Vocational Education System
}

\author{
Xiangzhong Meng ${ }^{1, \text { a }}$ \\ ${ }^{1}$ Dalian Vocational Technical College, Dalian, Liaoning Province, China \\ a776112625@qq.com
}

Keywords: education system; registered courses; management mode.

\begin{abstract}
This paper constructed a management mode of registered courses. By drawing on the experience of the higher vocational education in Australia, this paper analyzed the feasibility of this mode, expounded its characters and found that the crisscrossed reticular system of knowledge and ability is the key to implement this mode.
\end{abstract}

\section{Introduction}

With the advent of the knowledge era, it puts forward new requirements for the education innovation, quality education and the students' comprehensive vocational ability training in higher vocational colleges. The problem of curriculum reform has drawn great attention in the field of vocational education. The state has also attached great importance to the vocational education and regarded the reform and development of vocational education as an important way to promote the economic restructure and change the mode growth. In 2007, the project on the construction of national demonstration vocational colleges promoted the development of higher vocational education. In the process of rapid development of higher vocational education, course management mode has constantly developed and improved. Whether it adapts to the rules of modern vocational education directly affects the teaching quality of higher vocational education. The reform of the course management mode has become an important means of maintaining the advance of higher vocational education.

\section{The Registered Course Management Has Become the Essence of International Advanced Vocational Education Course Management Mode}

Taking the higher vocational education in Australia as an example to illustrate the scientific characters of the registered course management mode.

Australia regards vocational education and training as a whole. Those complete the vocational education and training in different levels will gain the corresponding qualification certificates within the framework of Australian training qualifications, including Qualification Certificate Level I, Qualification Certificate Level II, Qualification Certificate Level III, Qualification Certificate Level IV, diploma, advanced diploma, as well as bachelor degree certificate, graduate certificate of vocational education and graduate diploma of vocational education which are newly added in recent years.

Technical and Further Education (TAFE) is one of the Registered Training Organizations (RTO) in Australia. It is public and belongs to the state government. It is a training institution, engaging in technical and further education. TAFE must comply with the standards and regulations for registration issued by Australian Quality Training Framework (AQTF) and register according to the law. It receives the training quality assessment every five years and has obtained the above professional qualification certificates in each level.

The training package is the industry competence standards developed by each industry in Australia, approved by the state and widely implemented in the nation. Every three to five years, it will be revised. The training package only provides the competence standards instead of the ways to achieve 
the standards. Thus, the training package reflects the unity of Australian industry professional standards and the flexibility of the education and training institutions' implementation, as well as the unity of the above. For TAFE institutions, the training package is the basis for the development of courses. Australia has developed 800 kinds which include more than 2000 kinds of training packages. Such as: FNS30304[2] refers to the training package of Qualification Certificate Level III of financial services industry accounting. It requires thirteen competence units, the corresponding competence elements and competence standards. The thirteen competence units belong to three different categories. Among them, four industry core units stipulate the requirements of the core competence of financial accounting. Five sectoral core units stipulate the requirements of the core competence of Qualification Certificate Level III of accounting. Four elective units stipulate the requirements of the optional units and give the principles and content of elective. At the same time, the corresponding Qualification Certificate Level III of accounting provides eight competence elements and corresponding competence standards.

Through the above exposition, it can be analyzed that the Australian vocational education has formed a perfect certificate-oriented course management mode, which reflects the concept of course supermarket. The diploma of vocational education in Australia is issued by the government. This is similar to the public higher vocational universities and colleges which are the main parts of higher vocational education in China. Therefore, its course setting and management experience will contribute to the construction of the course management mode of vocational education in China, especially the feasibility of course supermarket.

\section{The Construction of the Course Management Mode Framework}

In the recent twenty years, we have made much exploration into the course management mode of China's higher vocational education in and found out some modes. However, the definitions of various modes are not quite clear. The main modes are listed as following. Firstly, the mode with floor-typed structure refers to the mode which divides the courses into four categories, namely public basic courses, specialized basic courses, professional courses and specialty-oriented courses. And the course management mode is conducted according to the order. Secondly, the mode with platform structure refers to the course platform which constructs the courses with different levels, that is, public basic courses, professional basic courses, professional or specialized courses. And the mode is conducted according to the chronological order with the vertical course arrangement mode. Thirdly, the mode with module structure refers to the mode in which the courses are combined into a variety of knowledge modules and competence modules according to the analysis of the basic knowledge, basic quality and professional skills which are required by different occupations or jobs. This mode of professional course system is constructed with competence. Fourthly, the mode with open structure refers to the mode which focuses on the application of the course system and the interaction with the enterprises through technological innovation and the formation of the modern apprenticeship.

The above modes have many shortcomings. Firstly, the courses are conducted according to different individuals. Thus, the course repetition and the unserious course setting may occur. Secondly, the teaching plan is fixed. In the implementation process, the utilization of teaching resource is not enough. Thirdly, the course resources are scattered and the course construction team is dispersed, which is not conducive to the improvement of courses. Fourthly, the courses are managed by subjects at different levels, which will easily lead to the low efficiency and the increased labor cost.

In order to solve these problems, this paper explored into the construction of the management mode of registered courses, and its main frame is shown in Fig. 1. 


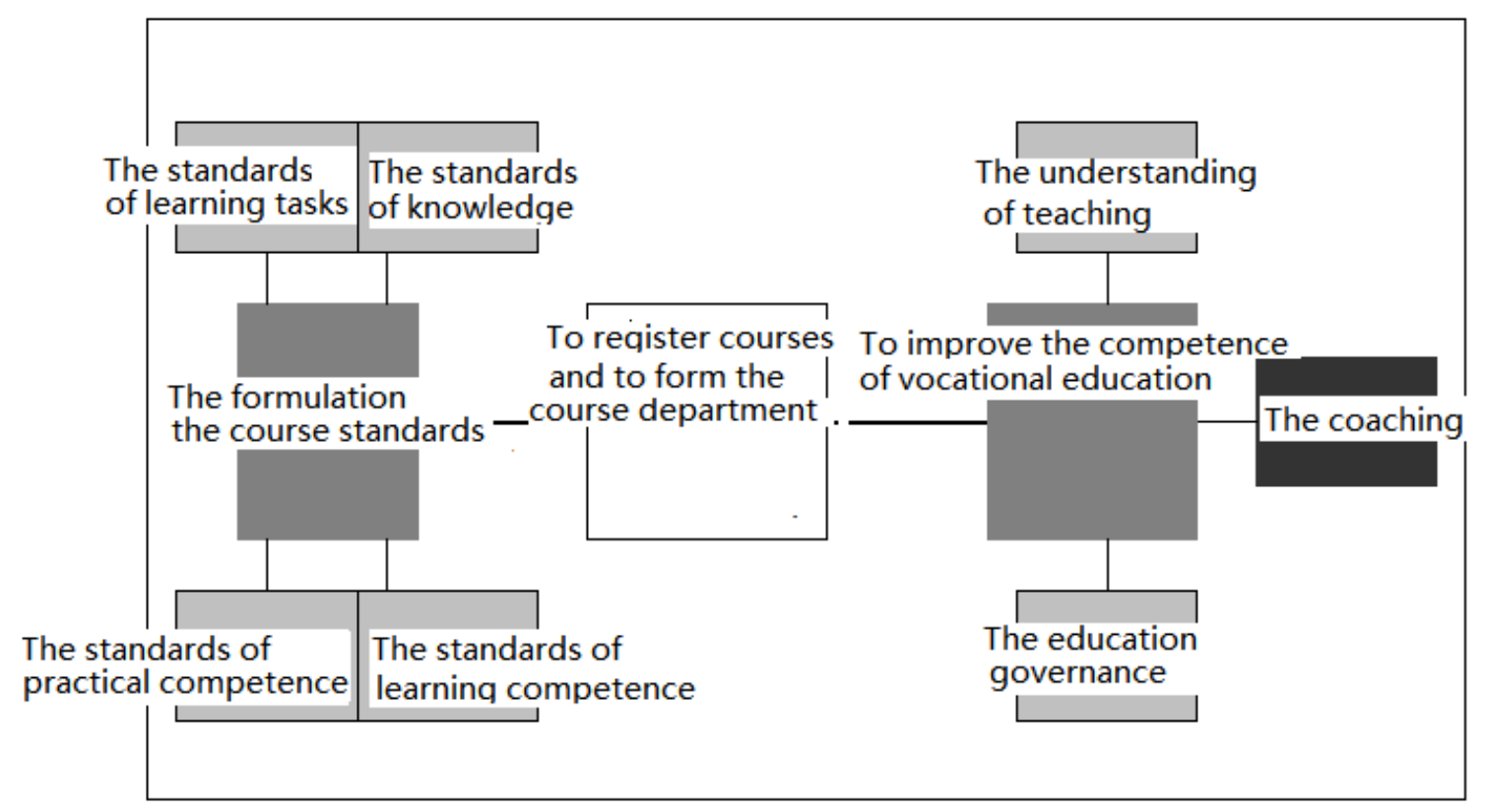

Fig.1 The management mode of registered courses

The framework of the registered course management mode is divided into three parts, the formulation of the course standards, the course registration and the form of course department, the improvement of vocational education competence. Among these, the improvement of vocational education competence belongs to the software construction while the course registration and the form of course department belongs to the hardware construction. The formulation of the course standards should be based on the learning participants' needs. The standards of learning tasks, knowledge, practical competence and learning competence will be separately formulated. The standards will directly affect the level of vocational education. The course department formed by the course registration is a normative teaching platform of vocational education. The competence of vocational education is the core of the mode operation, including the competence of the understanding of teaching, coaching and education governance, among which the teachers' coaching competence has been the focus.

\section{The Registered Course Management Mode is the Effective Mode of Course Management in Higher Vocational Education.}

Over the past ten years, the scale of China's vocational education has expanded rapidly and has been increasingly important in the whole education system. However, there are still some deep-seated problems affecting the healthy development of vocational education. Among these, the problem of the deviation of the talents' training system mainly reflected the gap between the talents' training and the market demand, which is directly caused by unscientific course management.

The main purpose of the registered course management mode involved in this paper is to solve the above problem and its characters are listed as following.

The courses are set up in accordance with the competence standards of the industry and the registration process is strictly conducted. The motivation of the formation of the registered course management mode is to establish the orderly vocational education market, to set up the courses according to the competence standards of the industry and to form a unique teaching paradigm.

The industry competence standards are the professional and technical ability assessment standards required by the jobs. Each of the standards is separately reflected in the course of teaching. According to the requirements of talent training program, the course department and specialty management committee formulate the course standards in accordance with the industry competence standards. The course department formulates the course implementation plan. After the approval of specialty management committee, they can register the courses. After the completion of course registration, the unified national qualification framework will be established to implement the effective connection 
between higher vocational education and other education and improve the management of vocational technology education. The employment access system will ensure the legal effect of the vocational qualification certificates to improve the effectiveness of vocational technology education and training management. The planning of vocational technology education should reflect the requirements of the vocational qualification certificates of the department of labor and human resource to achieve the unity of vocational education diploma and vocational qualification certificate. Through the collaborative management of government macro-control, training institutions and industry associations, we can achieve the coordination and unity of vocational technology education and vocational qualification training and establish a standardized, orderly nad unified market of vocational education.

To form the course department based on the specialties and to share the teaching resources. The registered course management mode forms the course department based on the specialties and sorts out the courses of the personnel training program. The number of the course set should be greater than or equal to the training programs required in the personnel training program. Taking the specialty of electronic as an example, the courses of electronic technique, electronic technology, assembly language programming and computer-aided design to strengthen the students' competence of electronic equipment maintenance and electronic control. Meanwhile, the students can also choose the courses of PLC technology control or electrical control from the course department of automation, so that we can avoid the repeated course settings and the course resources will be effectively used.

The essence of higher vocational education is to train the high-tech and application-oriented talents of production, construction, management and service. The vocational universities and colleges should handle the stable relationship between the diversity of social talent demand and the teaching objectives, make clear of the course objectives, be conducive to the construction of the employment-oriented talent training mode, handle the talents' training and the existing school running conditions and extensively use the social resources to achieve the goals of the courses.

To enhance the teachers' competence of vocational education. In the registered course management mode, the teachers' competence of vocational education is directly related to the quality of the course. It is the key to the success. This kind of competence includes three aspects, the competence of teaching knowledge, the competence of governance and the competence of coaching.

The competence of teaching knowledge is firstly original from one part of Shangshu, Learning. It refers to knowing the purpose and significance of education and understanding its true meaning of education. The part Learning in Shangshu proposes that only the teachers understand the cause of success or failure of education, can they be qualified for the job. For the vocational education, the education objects need not only the knowledge, but also the practical competence.

The competence of governance is mainly reflected in the governance structure of universities and colleges. We do not discuss it in this paper.

The competence of teaching is the key to construct vocational education competence. The teachers' competence of teaching is helpful to improve the level of professional construction in higher vocational universities and colleges. It is the key to the rapid development of higher vocational universities and colleges and the improvement of the teaching quality. With the deepening research and reform of higher vocational education, as well as the transformation of teaching philosophy from teaching to learning, higher vocational education has proposed higher requirements on the teachers' teaching competence.

Firstly, the teachers have to keep the advance of education, which is the key for teachers to adapt to the vocational education market and to meet the social demands. The teachers should be good at absorbing the latest scientific research achievements, put forward different ideas, actively apply the scientific research results in teaching and innovate the scientific and effective teaching methods.

Secondly, the teachers should have the competence of applying the teaching theory and methods in the classroom, which is the basic guarantee for the teachers to improve the teaching quality and cultivate innovative the talents. The teachers should not only be able to conduct in-depth study of the professional theoretical knowledge, but also be able to use the professional knowledge and experience to guide the students to apply their knowledge in practice. 
Thirdly, the teachers should have the competence to carry out the course development and design according to the standards. They should be good at the effective docking among the courses, the society and the market. They should design the courses which meet the requirements of the students' employment and the jobs.

Vocational education is mainly to cultivate the highly skilled talents in the economic and social development. Because of the one-sided understanding of this sentence, some higher vocational universities and colleges mainly focus on the practice and ignore knowledge in the process of teaching ability training. This is extremely wrong. For the teachers' knowledge and its structure, the American scholar, Shulman, has the greatest influence on the teachers' teaching knowledge. Shulman criticize the epistemology and methodology of the studies on the teachers' teaching behavior and put forward seven kinds of knowledge that support teaching, namely general pedagogical knowledge, pedagogical content knowledge, content knowledge, students' knowledge, knowledge of education environment, knowledge of education goals and course knowledge. According to Schulman's view and combined with the essential qualities of the teachers of higher vocational education, the key to implement a registered course management mode should be the crisscrossed reticular system of knowledge and ability. It is shown in Fig. 2.

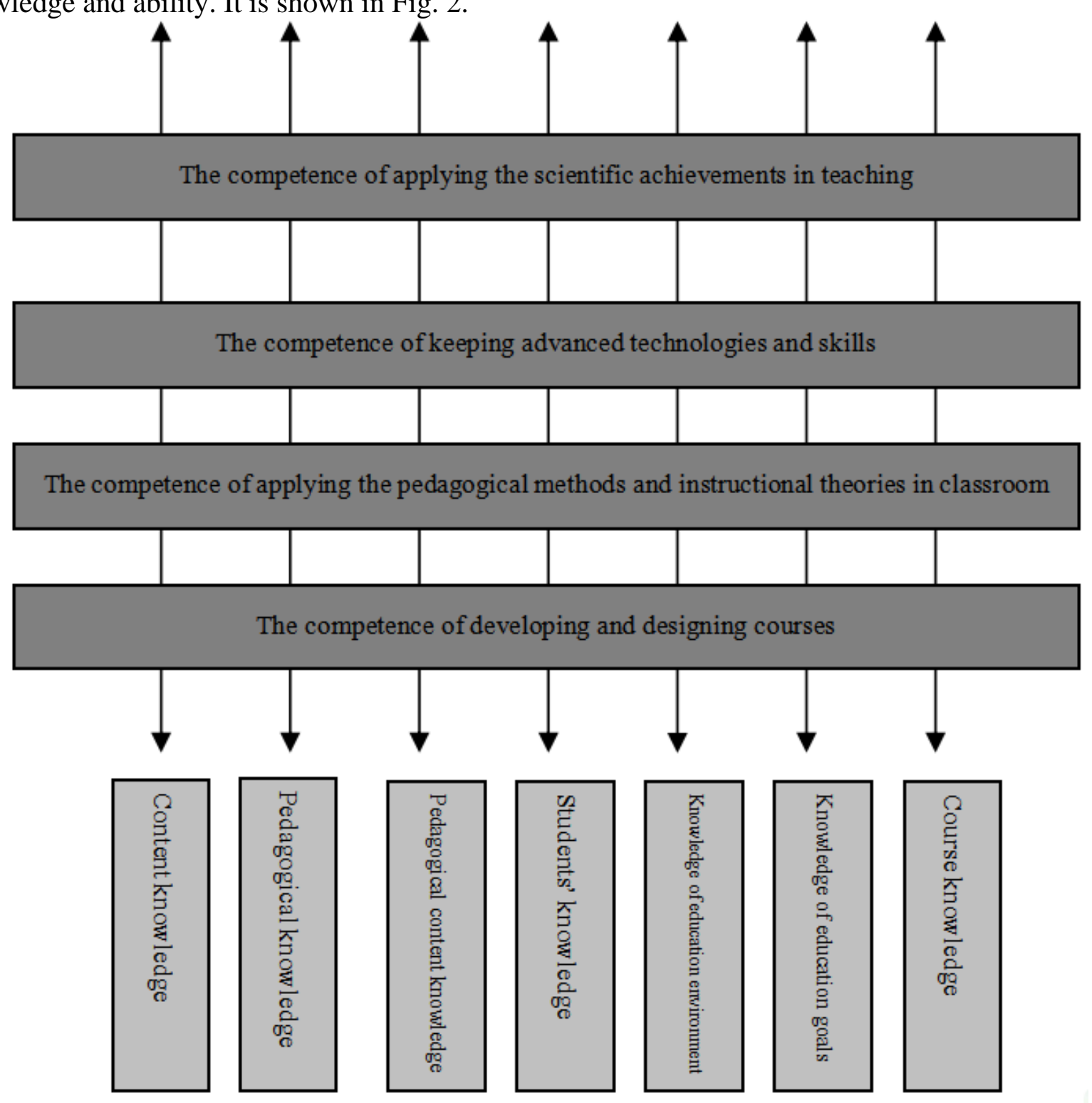

Fig. 2 The crisscrossed reticular system of knowledge and ability

The registered course management mode involved in this paper is a basic framework. There is no mature theoretical framework and the specific operations. The further construction requires the cooperation of the government, the society and the higher vocational universities and colleges. It is 
suggested that the relevant departments can formulate the implementation plans, including the guiding ideology, the methods, the steps, the principles and the objectives.

\section{References}

[1] Jin-shou Xu. The Character and Revelation of Vocational and Technical Education in Australia [J]. Vocational and Technical Education. 2009.

[2] Xing-dai Jiang. Educational Supermarket: Constuction and Pursuit of an Ideal Education [J]. Journal of Tianjin Normal University (Elementary Education Edition), 2008. 